\title{
VISUAL DESCRIPTION OF THE INDOOR SPACE OF REAL ESTATE IN CROWD-SOURCING ENVIRONMENTS
}

\author{
Sara Haghbayan \\ Faculty of Geodesy and Geomatics Engineering \\ University of K.N.Toosi in Tehran \\ E-mail: haghbayansara@yahoo.com \\ Mohammad Reza Malek \\ Faculty of Geodesy and Geomatics Engineering \\ University of K.N.Toosi in Tehran \\ E-mail:mrmalek@kntu.ac.ir \\ Behnam Tashayo \\ Faculty of Civil Engineering and Transportation \\ University of Isfahan \\ E-mail:b.tashayo@eng.ui.ac.ir
}

\begin{abstract}
Emerging the power of collective intelligence through crowdsourcing could create a clear path for visualizing real estate as well. One of the Crowdsourcing applications is describing the indoor space of a real estate. This paper aims to describe real estate in the context of spatial crowdsourcing. Qualitative and quantitative criteria were used in this study to describe the real estate space, topological relationships, directional relations, color, location, dimensions, and height as qualitative criteria. Quantitative criteria were selected as the dimensions and height. The proposed model was evaluated by two groups: those who had never seen the real estate and others that had already seen the same real estate. We implemented a website called SAMA ${ }^{1}$ to evaluate the proposed model with crowdsourcing data using online collaborative tools. SAMA is using tools, such as a sketch plan, photo, text, virtual tour, and visual descriptions. To evaluate SAMA, we compared it with four representative commercial websites, and the impact of the tools was precisely examined. The obtained results demonstrate that the proposed model can be utilized to visually describe the indoor space of real estate in crowd-sourcing environments.
\end{abstract}

Key words: crowdsourcing, indoor space, visual describing, real estate, sketch plan.

JEL Classification: L85, R00, R21.

Citation: Haghbayan, S., Malek, M.R., Tashayo, B. (2020). Visual description of the indoor space of real estate in crowd-sourcing environments. Real Estate Management and Valuation, 28(3), 91-103.

DOI: https://doi.org/10.1515/remav-2020-0026

\section{Introduction}

Real estate is among the needs of humans because it provides shelter and access to jobs, as well as

\footnotetext{
1 SAMA is the acronym of the Persian words of system, volunteered, and real estate.
} 
impacting health (Kurraz \& Ziara, 2015). According to United Nations (United Nations Centre for Human Settlements), in 1975, approximately $38 \%$ of the world's population lived in urban areas, and they estimate that this figure will reach $60 \%$ by the year 2025 (Montoya, 2003). Due to the increasing urban population and the high prices of land, living in apartment buildings has become common nowadays (António et al., 2014; Ghuzlan \& Al-Omari, 2016). The quality of apartments is a significant factor influencing overall residential satisfaction and satisfaction with the residential area (Boumová \& Zdráhalová, 2016; Sahraoui et al., 2016). In 2010, the results of a survey in Korea showed that, among various residential properties, $59 \%$ of the population has apartments as their main place of residence. In Finland, $80 \%$ of people live in apartments (Pekkonen et al., 2015), especially the younger population; however, the poor design of the housing properties cannot meet the needs of different customers (Lee \& Ha, 2013). It is moreover interesting to note that, in developed countries, people spend more than 90\% of their time indoors (Fasolo, 2016; Frontczak \& Wargocki, 2011).

Traditionally, the process of searching for and choosing real estate has been based on face-to-face meetings, physical visits to the real estate, and a careful survey of their properties. Typically, buyers have to spend much time and induce significant costs to acquire real estate information by arranging times and individual visits (Omidipoor et al., 2019). In 2002, up to 50\% of prospective American homebuyers used the Internet through various real estate sites to search for new homes. Different users may have different requirements for system features and functionality. The abundance of publicly accessible real estate property data, data distribution, distribution for response time, and distribution for availability will attract more users and increase the reputation of a website (Lin et al., 2003). The advancement of Web 2.0 technologies provides the web infrastructure that empowers mapping citizens as voluntary sensors, producing large data sets known as crowdsourcing (Chow et al., 2016). This phenomenon has a significant effect on geographic data production and sharing, because individuals can act as both data producers and users (Mohammadi \& Malek, 2015b). With the rapid growth of smartphones, more than 1.5 billion people worldwide have been covered (Zhao et al., 2016). Smartphones have become an essential part of everyday life in many countries, which means that there is more than one handset for each person (Gunnar \& Mats, 2004). Many affordable sensing-based technologies are now available to support building modeling and indoor surveying that are used by professionals. Smartphones bring the opportunity to fill the indoor information gap that we are facing worldwide. Smartphones brought about crowdsourcing phenomena (Kalantari \& Nechifor, 2016). One of the various types of data that can be collected by crowdsourcing is digital photos (captured by Geotagging). Geotagging is the process of adding geospatial data to different forms of media (such as texts, photos, or videos) with location data, latitude, and longitude (ZEINALI, 2013). Most of the textual data contains location information embedded within the feedback, i.e., the issues are related to certain geo-locations (Chen et al., 2017). In 2006, the term crowdsourcing was introduced by Howe, which is the combination of the words "crowd" and "outsourcing". Thus crowdsourcing refers to the outsourcing of micro-tasks to large volumes of people to perform a task that would not have been possible through more traditional means. The crowdsourcing approach is how a group of people may converge on the solution to a problem that an individual, even an expert, may be unable to solve. It also refers to the ability of the crowd to converge on the truth (Capineri et al., 2016).

This study aims to describe and retrieve real estate by using visual components through crowdsourcing. Moreover, it describes the indoor information of the real estate by using various tools, such as sketch plan, photo, text, virtual tour, and visual descriptions.

\section{Literature review}

Several studies have already been conducted concerning how the users understand the interior environments and their conditions (Frontczak \& Wargocki, 2011). Sonawane et al. (Sonawane \& Mhaske, 2016) used GIS to analyze the amount of light in the indoor space of an apartment. Boumova et al. (Boumová \& Zdráhalová, 2016) used the qualitative method to analyze the perception of topological relation in the indoor space of the estate between two groups of architects and the public. They found that the topological relation plays a vital role in distinguishing between these two groups. Vartanian et al. (Vartanian et al., 2015) researched the effect of ceiling height on mood and analyzed the perception of the appearance of the space. Meyers et al. (Meyers-Levy \& Zhu, 2007) investigated the effect of colors on mood and the perception of the space. Falomir et al. (Falomir et al., 2013) created qualitative patterns for describing distance, shape, color, direction, and topology. Lee et al. (Lee \& Ha, 
2013) implemented a system called "Customer Interactive Building Information Modeling" (CIBIM) to improve the relationship between customers and designers of real estate. Gustafsen et al. (Gustafson et al., 2000) examined different aspects of human-computer interaction in a multi-dialog system during a project. This system provides users with features such as a virtual tour and graphical information on the map. Salleh et al. (Salleh et al., 2008) noted that Estate and Housing Developers' Association Malaysia (REHDA) was the only database of real estate displaying information on and photos of some real estates. The user needs to go to the website to obtain more details about the real estate and its architectural information. The photos and virtual tour may facilitate the searching process and communication between the buyers and sellers of the real estate (Allen et al., 2015). According to research, when searching for listings online, users will examine the photos first. Most of the users' time is spent browsing through the various photos. Users will then review the basic description of the house (Seiler et al., 2012). By using a virtual tour, viewing the indoor space of the real estate can be possible without physically going to the actual place (Ching, 2018). Most real estate websites allow the user to search by list price, location, age, number of bedrooms, and number of bathrooms, as well as interior and exterior photos. Some sites have a map-based search feature (Poursaeed et al., 2018). Information provided by websites or real estate consultants about a property can be vague and include misleading photos that have been photoshopped or use wide-angle lenses, and essential details can be left out (Fasolo, 2016).

Uttal et al. (Uttal et al., 2006) pointed out that an excellent way to measure the precision and accuracy of people's perception of the observed space would be utilizing a virtual environment in an outline. Muhanna et al. (Muhanna \& Wolf, 2002) examined the potential impact of the Internet on the residential estate industry. They predicted that the number of buyers and sellers would increase the discovery of estate information through the Internet. The National Association of Real Estate also confirmed the validity of this result. On the other hand, Ho et al. (Ho et al., 2015) stated that using the Internet might not reduce the search time. Much of today's content on the web is now user generated, meaning anyone can go online and post photos, videos, blogs, and more. Many sites offer the ability for users to weigh in on topics by leaving comments, or review products or services. Several studies on measuring trust and a sense of community within crowdsourcing environments have been carried out. Users are willing and ready to write reviews on their experiences in their apartment buildings ( $\mathrm{Lu}$ et al., 2016).

Several sites allow for online user reviews, comments, and forums. Yelp's website ("Yelp.com"), is a crowdsourced local business review and social networking site. Users can rate and leave a review, share experiences, and check in to a location with their phones to upload photos of their experiences, including the real estate visited (Hosseinpour et al., 2019; Singh et al., 2019). Nevertheless, despite its numerous advantages, crowdsourcing also suffers from a general lack of quality assurance (Mohammadi \& Malek, 2015a). Five approaches for controlling the quality of crowdsourcing have been distinguished (Antoniou \& Skopeliti, 2015).

\section{Selection of visual criteria and their modeling}

The residential estate can be displayed using topologic and geometric descriptions defined in Iso 19107 (Becker et al., 2009; Jamali et al., 2016). In geometric descriptions, the size and situation of each residential estate are defined by geometric descriptions. However, the limitation of the space of the geometric design is defined by topologic descriptions (Kaklauskas et al., 2007). Topological relations, such as proximity and connections, are directly obtained from 3D geometry. Both geometry and topology spaces have variables, stipulations, and targets. The geometry of the indoor space of a real estate aims to minimize heating and lighting costs, wasted space and access areas.

In contrast, the purpose of the topological relation is to minimize the geometrical optimization result. Le Yaouancing et al. Early GIS models were deeply influenced by quantitative models and geometrical representations of space (Le Yaouanc et al., 2010). Qualitative and quantitative criteria were used in this study to describe the real estate space, topological relationships, directional relations, color, location, dimensions, and height as qualitative criteria. Quantitative criteria were selected as the dimensions and height. The following qualitative and quantitative criteria describing the space are explained. 


\subsection{Topological relationships}

The topology-based approach can even merge multiple models and thus, eliminate the complexity of aggregation models (Zhao et al., 2012). Topological relations in residential real estate play a key role in maintaining privacy (Boumová \& Zdráhalová, 2016). A topological relation is an important subject in GIS. In traditional methods, such as Computer Aided Design, describing the relationship of the vicinal building space was complicated and often incomplete (Jamali et al., 2016). Proximity plays a vital role in the topological relation (Medjdoub \& Yannou, 2000).

\subsection{Directional relation}

The sense of direction is a natural ability of humans. Generally, people can use different approaches, such as cardinal directions and relative orientation relations, for recognizing directions and the internal configuration of space. We consider $\mathrm{O}$ as the origin of the coordinate system in the space, before summarizing the six directions in three measurements of length, width and height, which are perpendicular to each other. Therefore, the living space has three dimensions and all phenomena visible to humans have three measurements of length, width and height. Soleymani developed a model based on the three $\times$ three matrix (Soleimani, 2015).

\subsection{Color}

Color is an essential component that affects the space dimension and people's state of mind (Oberfeld et al., 2010). One may even claim that color is the most used component in indoor space. Using colors makes a room appear bigger or smaller, a ceiling higher or lower, and a hallways broader or narrower. If the ceiling is brighter than the door and wall, the room looks higher. If the walls are brighter than the ceiling, the room seems shorter. Therefore, the color of a space has a significant effect on the height, depth, width and general perception of space (Oberfeld et al., 2010).

In addition to the effectiveness of colors in modifying the brightness or darkness of space, color also affects people's health. Warm colors have a positive effect on people's health as they affect sympathetic nerves (Meyers-Levy \& Zhu, 2007). Since the yellow color reflects more light, it makes space look brighter (Sonawane \& Mhaske, 2016). Cold colors, such as blue and purple, result in peace of mind and affect the parasympathetic nerves (Meyers-Levy \& Zhu, 2007).

\subsection{Geographic location}

Geographic location is a significant and effective factor in choosing a real estate since it affects the incoming light of the indoor space. Generally, people are interested in the brightness of their real estate. Direct sunlight makes the indoor space more pleasant and larger. Although direct sunlight has a lot of positive effects, excess incoming light causes visual discomfort, especially in older people (Veitch et al., 2012). In another study, the amount of light in the indoor space of the estate was analyzed using GIS. This study showed that southern-facing estates receive more light and have the maximum light in the living room, while southwest-facing estates receive more light than southeast ones. Northern-facing flats receive less light than southern flats, while northwest ones receive more light than northeast ones (Sonawane \& Mhaske, 2016).

\subsection{Dimensions}

The dimensions of interior space are based on the area of the property. Some people prefer to live in a bigger space, while others, especially young people, prefer to live in a smaller place (Pekkonen et al., 2015). If people wishing to live in a bigger place have low incomes, the probability of choosing an estate in the suburbs will increase (Ho et al., 2015). The sizes of different spaces of residential estates (such as kitchen, bedroom, and bath) were classified into small, average and big, according to Islamic considerations. In this way, the cost of housing decreases up to $20 \%$ while ensuring an adequate environment and suitable conditions (Kurraz \& Ziara, 2015).

\subsection{Height}

Height is effective in creating volume, light processing, and sound. The height affects indoor space as well as middle space or corridors. In this research, we define the height as the distance from the floor to the ceiling. The height can be very effective in influencing the mental health of the estate residents as estates with a height of more than $8 \mathrm{ft}$. can create a sense of freedom (Meyers-Levy \& Zhu, 2007). In the USA, people tend to add $2 \mathrm{ft}$. or $0.61 \mathrm{~m}$ to the standard ceiling height of $2.24 \mathrm{~m}$. Although greater 
ceiling height comes at a higher cost, the people of the USA tend to pay more for properties with a greater ceiling height than the standard size (Vartanian et al., 2015). Psychologically, properties with more ceiling height look bright and cheerful since they create more volume and look bigger.

\section{Crowdsourcing Website}

The proposed system is an example of crowdsourcing in real estate, which has the potential to considerably contribute to solving the existing problems. The proposed crowdsourcing website is called SAMA. SAMA is an acronym of the Persian words of system, volunteered, and real estate. This website includes seven sections: homepage, website introduction, registration, login information, report, and evaluation. On the homepage, the user first determines price range, region and neighborhood, area, real estate type, the number of bedrooms, the building year, and transaction type, including purchase, pre-purchase, mortgage, or rent. Following this, according to the information in the database and the user's choice, the system displays the most suitable properties in two different ways. The first is in the form of a map that shows indoor, middle, and outdoor attribute information for the real estate, while the second shows the information of the real estate along with photos of the view and indoor space of that real estate.

Some factors and limitations reduce the quality of the interior spaces, such as the shape and area of land, maximizing the number of building units for more profit, and lack of builders' knowledge on the effectiveness of quantitative and qualitative criteria. The real estate description is very visual. Most people use positive and negative visual concepts to describe the real estate that they have seen. Positive visual concepts include cheerful and bright, well-designed, and shapely. Negative visual concepts include shapeless, badly-designed and dim. Shapeless is connected with the restricted shape of the land. The shape of the land may be an irregular quadrilateral, such as a triangle or a trapezoid. This causes some of the interiors of residential real estate to be angular, which is often undesirable. Most people prefer to choose apartments with a quadrilateral interior, such as a square or a rectangle. Badly-design apartments are those which do not have the appropriate directional relations and topology. The area of these apartments looks smaller than its real area. For example, the door of a toilet should not be opened in the living room. In such a way, the topological relationships between indoor spaces create privacy. Dim apartments refer to apartments that are low in height, and in which the color of the ceiling, walls, and floor are dark. Some architects use quantitative and qualitative criteria because of their high level of knowledge and experience to enhance the quality of the indoor space and cover some of the drawbacks. Fig. 1 shows positive and negative visual descriptions of the indoor space of residential real estate, while Fig. 2 shows the relations between the visual components and qualitative and quantitative components and display tools.

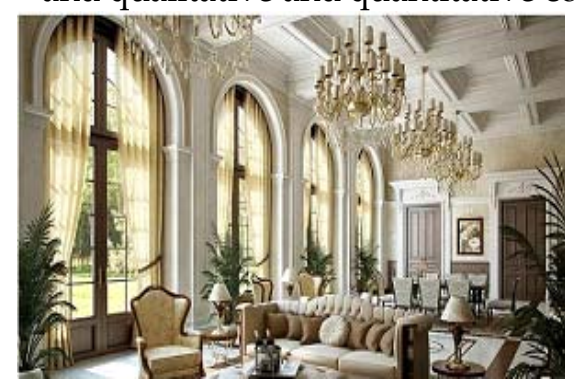

bright and cheerful

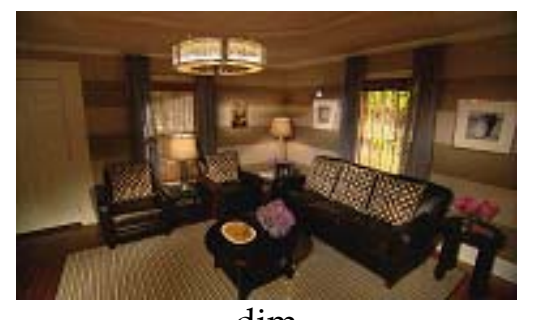

$\operatorname{dim}$

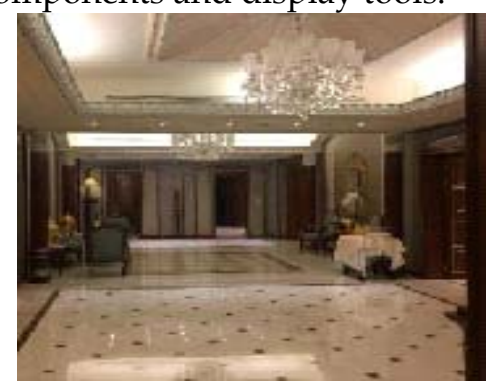

well-designed

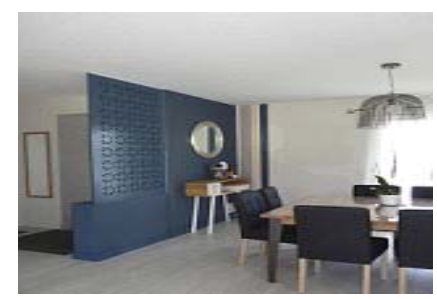

badly-designed

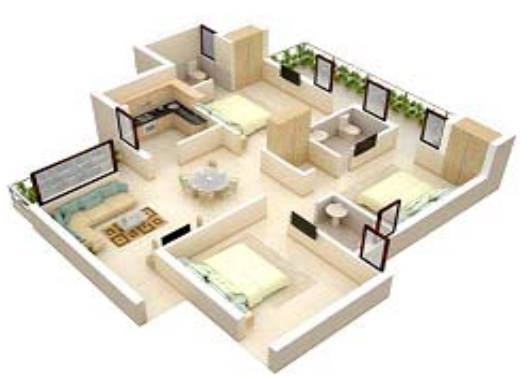

shapely

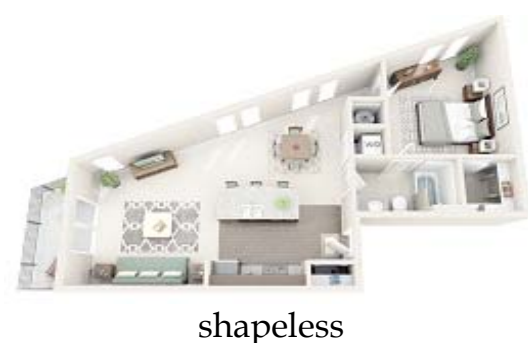

Fig. 1. Positive and negative visual describing of the indoor space of real estate. Source: own study. 


\section{$\$$ sciendo}

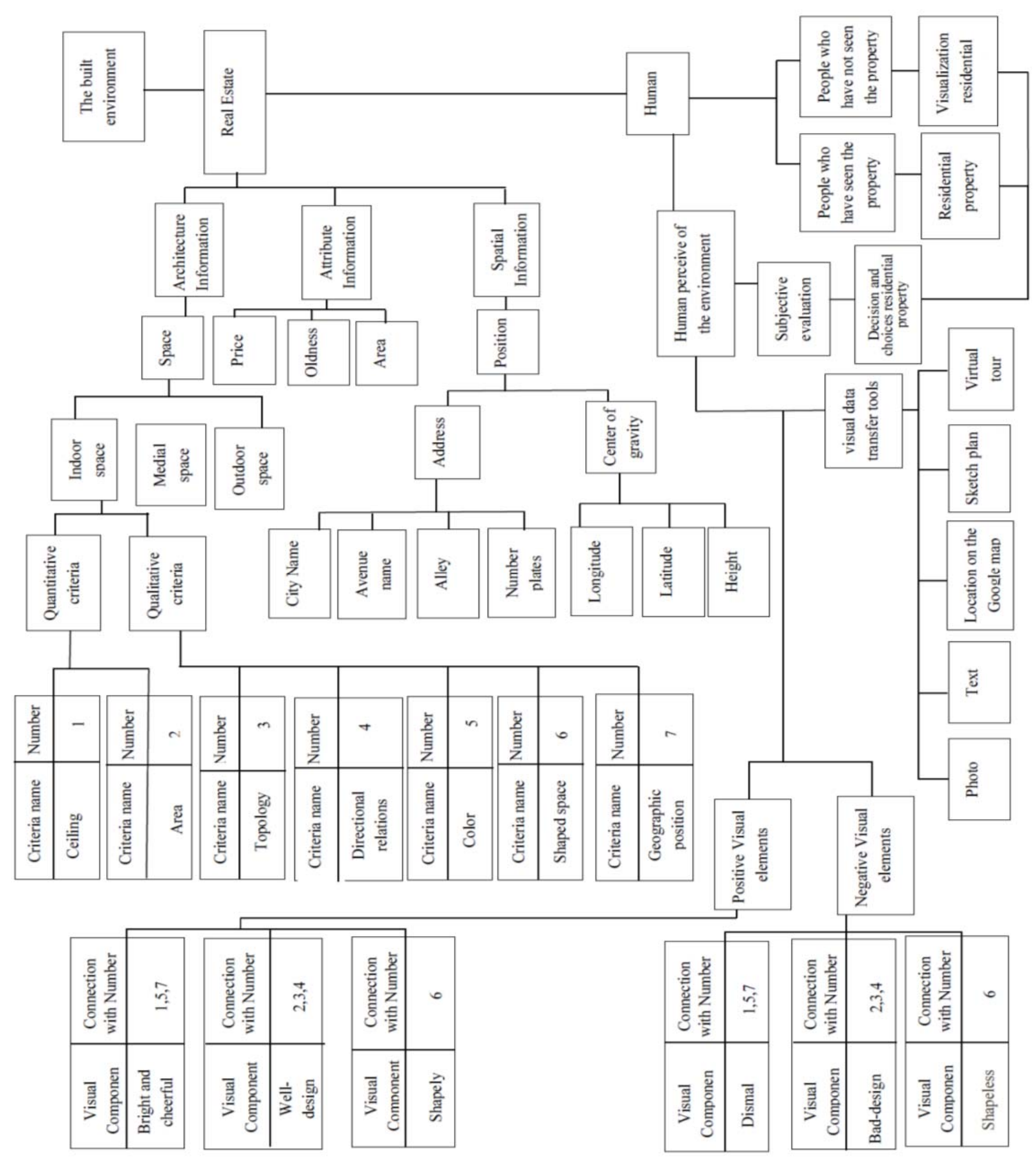

Fig. 2. The relations between visual components, qualitative and quantitative components and display tools. Source: own study.

The proposed website can provide further services, as the system can ask for some extra information from the users, such as their age, gender, degree of education, motivation, and any disability. If the user is willing to supply this information, it will suggest some properties that match the user's needs.

This study involved the comments of visitors on each real estate to ensure quality. The motivation of all users is considered as a means of improving results when receiving information. The considered disabilities in this research include backache, sore feet, heart disease, respiratory problems, and depression. For example, if the user is old, has a backache or sore feet, properties with an elevator or a location on the first floor will be suggested. For users who have depression, properties with bright colors are proposed. In the case of users suffering from heart disease or respiratory problems, properties near green spaces will be suggested. Therefore, without any cost, users can find properties 
according to their conditions. The proposed crowdsourcing website works as a guide absentia and is free. Fig. 3 shows the SAMA website.

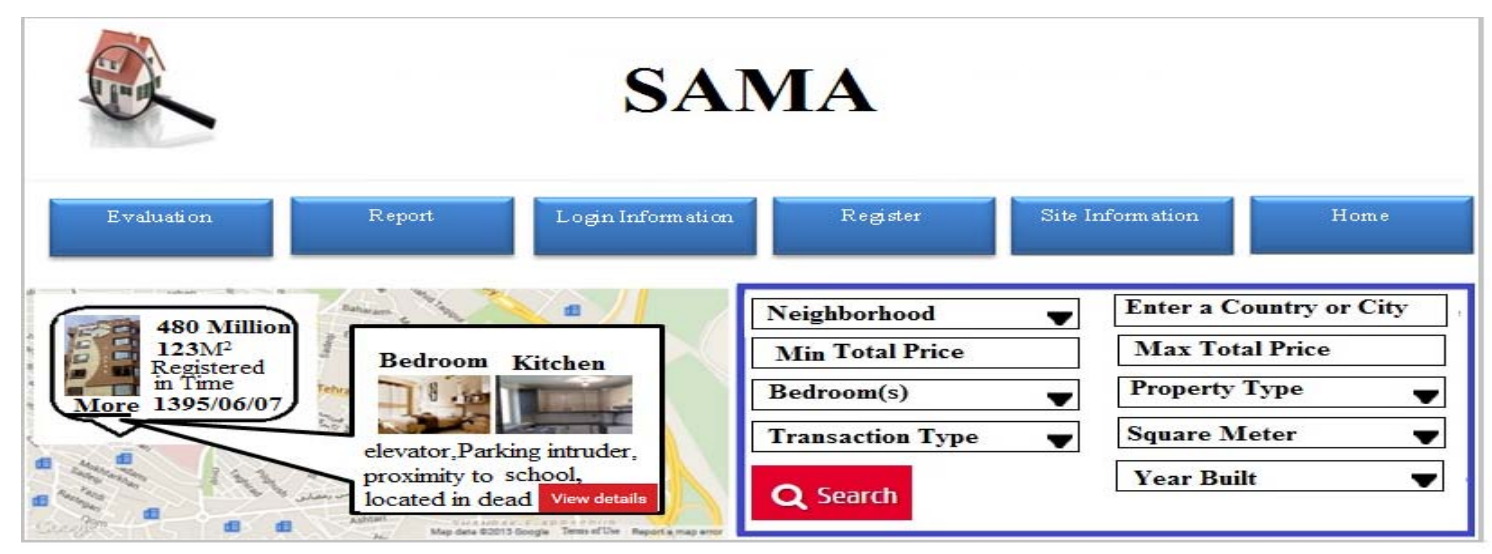

Fig. 3. SAMA implementation software. Source: own study.

The proposed crowdsourcing website also asks for some information, such as demographics, state of health, and the user's motive in selecting the real estate. By doing so, it can offer better recommendations. Users that do not like to register on the website can still access the information on the site.

\section{Practical evaluation}

In this paper, we divided the visual elements into several categories and each category was divided into several subsets. For example, height has been divided into three subsets: short, long, and average; color into two subsets: light and dark; and the shape of spaces according to indoor angle into two subsets: vertical and non-vertical. Geographic location has been divided into seven subsets of north, south, east, west, north-south, east-west and other. The topological relationships considered in this article are included, disjoint, meet/overlap, and include. Directional relations were also divided into four subsets: top, bottom, left, and right.

Here, we consider the average ceiling height of the real estate to be about 2.8 meters. A value larger than $2.8 \mathrm{~m}$ is classed as high, while a smaller value is classed as low. In the category of colors, white or cream colors are deemed bright colors, while other colors, such as gray and brown, are classified as dark. We considered square and rectangular shapes as vertical shapes, while the other shapes, such as triangular and trapezoidal shapes, are non-vertical.

Figure (4) shows the directional relation between indoor spaces of a real estate. A sketch plan is a reasonable means that describes the topological relation and directional relations of indoor space briefly.

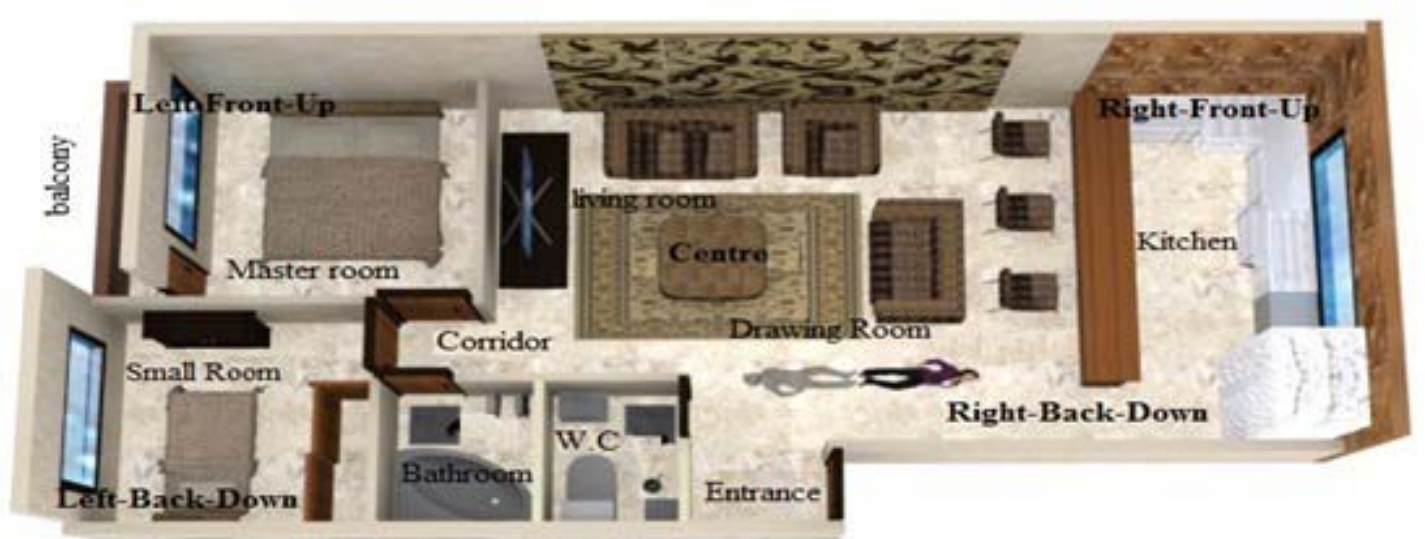

Fig. 4. Directional relation between indoor spaces of a real estate. Source: own study.

In the context of Geographic Information Systems (GIS), the spatial relationships existing between geographic objects play a central role both at the spatial queries definition and processes 
Table 1

Topological relationships for demonstration problem

\begin{tabular}{cl}
\hline Constraint Type & Constraint \\
\hline Path & In each apartment, there must be a path from the Kitchen to the Living Room \\
\hline Path & In each apartment, there must be a path from each Bedroom to the Living Room \\
\hline Connectivity & Public Entry must connect to the living room of each apartment \\
\hline Connectivity & Public Entry must connect to an external wall \\
\hline Connectivity & All bedrooms must connect to an external wall \\
\hline Corridor & Corridor line connecting Units cannot intersect \\
\hline Meet & In each apartment, the Living Room may meet with the toilet \\
\hline Disjoint & $\begin{array}{l}\text { In each apartment, there should be a disjoint kitchen from the Bedroom and } \\
\text { Living Room }\end{array}$ \\
\hline Include by & In each apartment, Bedroom may be Included by Bathroom \\
\hline Include & $\begin{array}{l}\text { Spaces that are connected to an external wall must lie on the boundary include } \\
\text { of spaces }\end{array}$
\end{tabular}

Source: own study.

Table 1 show the topological relationships used when creating the visual model. In our model, we used a lower resolution level of eight topological relationships between the regions in the plane. The "Include" relation is a substitution for both cover and contains relationships. This research aims to define the indoor space of the residential estate and, for this reason, the spatial relations should first be determined relative to each other. After this, we can use these relations to determine the relative position of each location in the space.

Table 2

Topological relationships between indoor spaces of the real estate

\begin{tabular}{cccccccc}
\hline Balcony & $\begin{array}{c}\text { Master } \\
\text { room }\end{array}$ & $\begin{array}{c}\text { Small } \\
\text { room }\end{array}$ & Bathroom & WC & $\begin{array}{c}\text { Living } \\
\text { room }\end{array}$ & Kitchen & $\begin{array}{c}\text { Indoor of } \\
\text { space }\end{array}$ \\
\hline Disjoint & Disjoint & Disjoint & Disjoint & Disjoint & Meet & - & Kitchen \\
\hline Disjoint & Disjoint & Meet & Disjoint & Meet & - & Meet & Living room \\
\hline Disjoint & Disjoint & Disjoint & Meet & - & Meet & Disjoint & WC \\
\hline Disjoint & Disjoint & Meet & - & Meet & Disjoint & Disjoint & Bathroom \\
\hline Disjoint & Disjoint & - & Meet & Disjoint & Disjoint & Disjoint & Small room \\
\hline Include & - & Disjoint & Disjoint & Disjoint & Meet & Disjoint & Master room \\
\hline- & $\begin{array}{c}\text { Include } \\
\text { by }\end{array}$ & Disjoint & Disjoint & Disjoint & Disjoint & Disjoint & Balcony \\
\hline
\end{tabular}

Source: own study.

Topological relationships between the indoor objects illustrated in Fig. 3 are presented in Table 2.

Table 3

Directional relation between indoor spaces of a real estate

\begin{tabular}{|c|c|c|c|c|c|c|c|}
\hline Balcony & $\begin{array}{l}\text { Master } \\
\text { room }\end{array}$ & $\begin{array}{l}\text { Small } \\
\text { room }\end{array}$ & Bathroom & WC & $\begin{array}{l}\text { Living } \\
\text { room }\end{array}$ & Kitchen & $\begin{array}{l}\text { Indoors of } \\
\text { space }\end{array}$ \\
\hline RFU & RFU & RFU & RFU & RFU & RFU & - & Kitchen \\
\hline RFU & RFU & RFU & RFU & RFU & - & RFU & Living room \\
\hline LBD & LBD & LBD & LBD & - & LBD & LBD & WC \\
\hline LBD & LBD & LBD & - & LBD & LBD & LBD & Bathroom \\
\hline LBD & LBD & - & LBD & LBD & LBD & LBD & Small room \\
\hline LFU & - & LFU & LFU & LFU & LFU & LFU & Master room \\
\hline- & LFU & LFU & LFU & LFU & LFU & LFU & Balcony \\
\hline
\end{tabular}

Source: own study. 
The directional relationships between the indoor objects illustrated in Fig. 3 are presented in in Table 3. To express directional relationships, the qualitative terms front, up, back, down, left, and right are applied. These relationships are defined as the relations with the center of the living room. In this table, we use the first letter of the direction. For example, instead of "back-left-front", we have recorded "BLF".

Users should provide the attribute of the real estate and upload some photos and videos from the interior of the place. The system also asks a few alternative questions to find out about the indoor space of the real estate. In this study, the space of real estate is divided into three parts, which are namely indoor space, middle space, and outdoor space. The middle space includes the staircase and balcony. The interior spaces include Entrance, Kitchen, Living room, WC, Bathroom, Corridor, and Bedroom. Outdoor space is the location of the real estate property, and includes the Major Street, Local Street, dead end, and alley.

The proposed system can display the indoor information of the real estate by using various tools, such as a sketch plan, photo and virtual tour, and visual descriptions of the real estate. These descriptions are automatically displayed on the SAMA website by alternative responses of the users. The middle space information is automatically displayed using photo and system descriptions. Finally, the outdoor space information of the real estate is displayed in the proposed system by locating the real estate on Google map along with descriptions that the users saw while visiting the real estate. Thus, this system helps those who have not yet seen the real estate to visualize it. If people give demographic information, properties tailored to the users' requirements will be suggested to them. Fig. 5 shows the typical residential real estate information and description of indoor space using visual components and display tools. Fig. 6 shows a flowchart of the SAMA website.

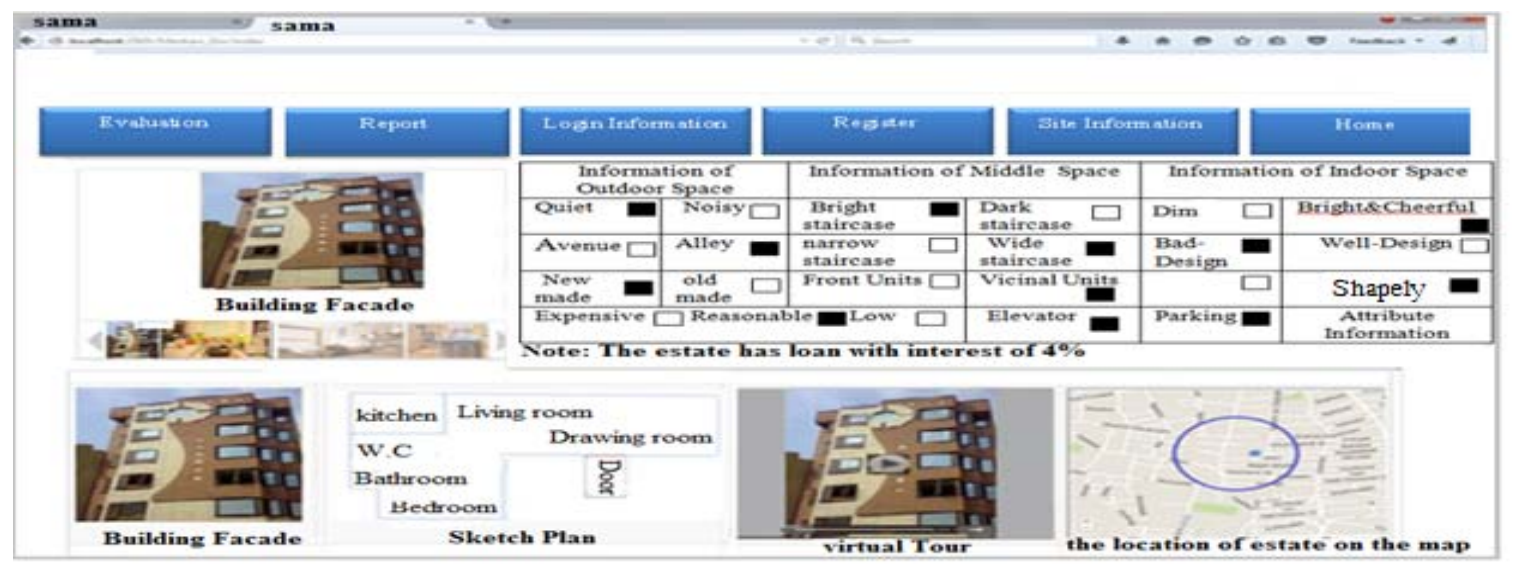

Fig. 5. The typical residential real estate information and description of indoor space using visual components and display tools. Source: own study.

The similarity assessment of real estate descriptions in two groups, including the first group that had not seen the real estate yet and the second group that had seen it beforehand, was examined. The research data were obtained from 110 men and women who agreed to fill out the questionnaire. The average age of those questioned was 38.47 years. The results of these surveys are presented in Figs. 5,6. In this research, it was assumed that all people have the same spatial perception ability, verbalization and visualization abilities, and people who visit the real estate have a smartphone. Furthermore, it was assumed that all people had been trained to describe residential properties with the minimum required information in their mother tongue or their native language. In other words, all people have visual literacy. For this reason, if the applied criterion is not particularly specialized, each user's data will be given equal importance to obtain optimal respect.

The effectiveness provided by the website features was surveyed, with the results showing that the sketch plan, virtual tour, photo, location on the Google map and text have the most impact on the visualization of the real estate, respectively, as shown in Fig 7. 


\section{S sciendo}

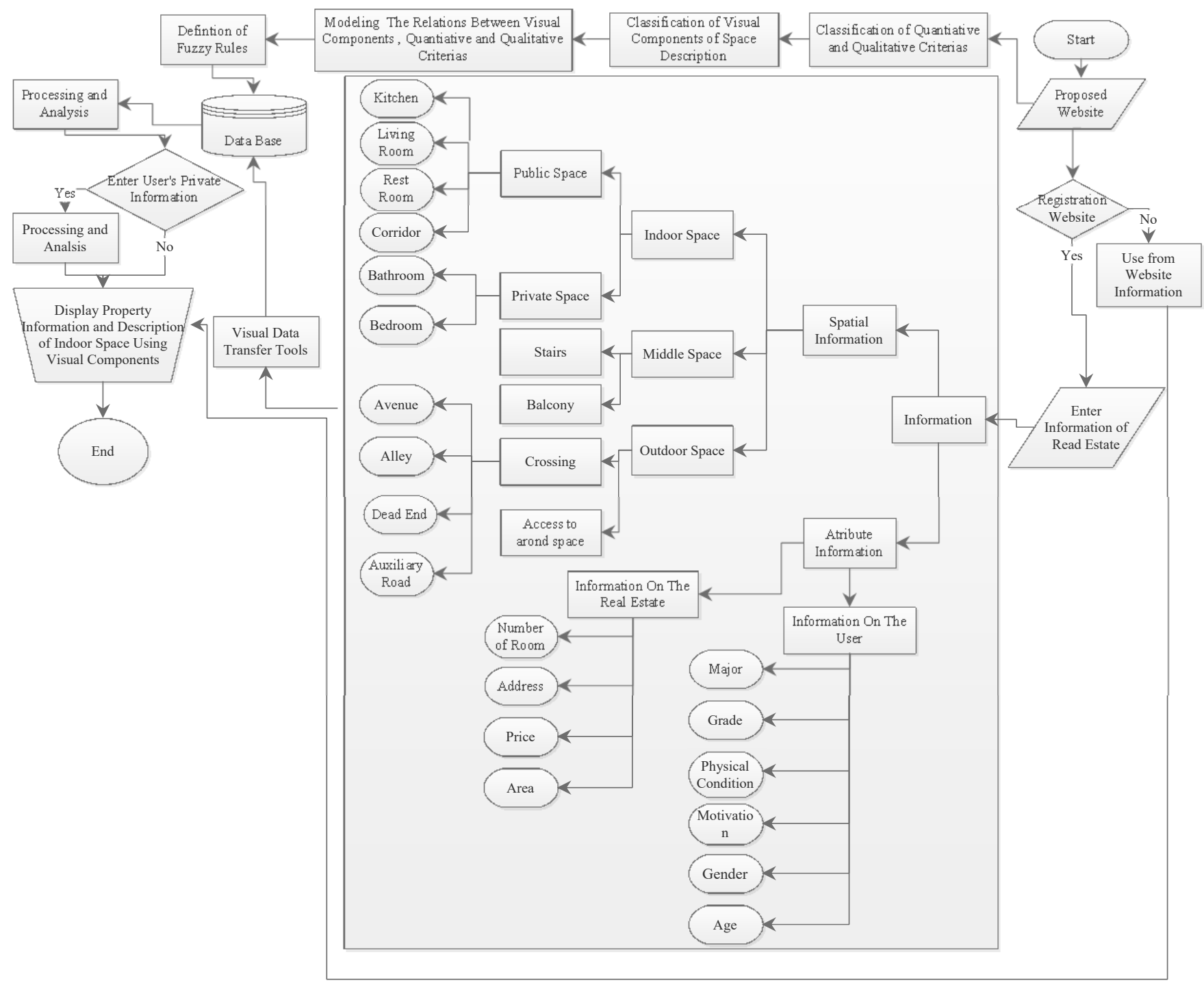

Fig.6. Flowchart of the SAMA website. Source: own study.

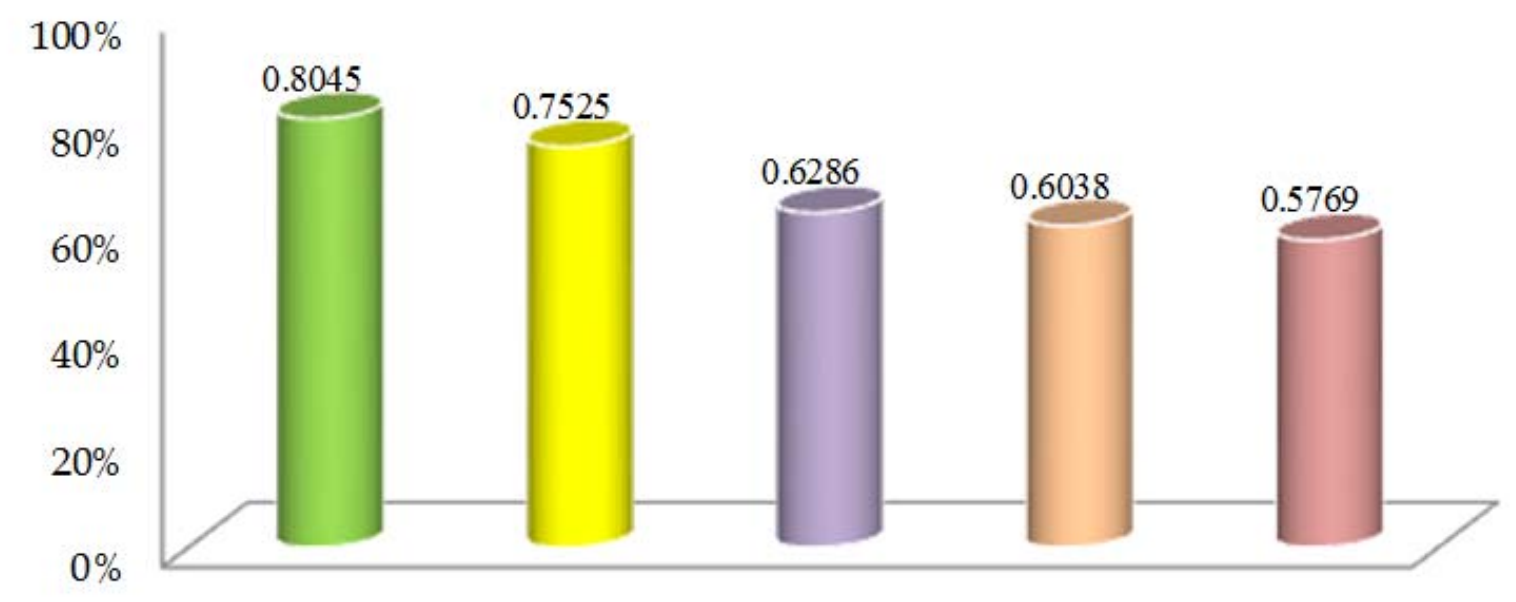

Sketch plan $\approx$ Virtual tour $\backsim$ Photo $\|$ Location on the Google map $\approx$ Text

Fig. 7. The Effect of the Visual data transfer tools. Source: own study. 
We used the same statistical population (110 people) to evaluate the effectiveness of the proposed website and its ability to compare with popular and user-friendly commercial websites. These websites include Delta, Dodota, Divar, and Iranestate. Figure 8 shows the results of satisfaction assessment from selected sites compared to the proposed websites.

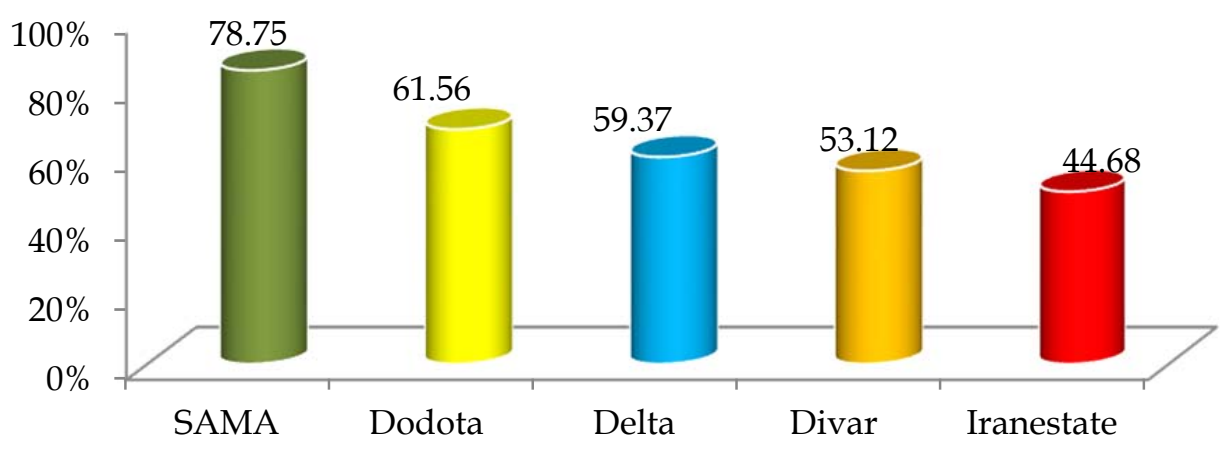

Fig. 8. The comparison chart of SAMA with other reviewed estate sites. Source: own study.

\section{Conclusions}

This study proposed a framework to increase the use of crowdsourcing in the description of residential properties. We designed a model to describe and represent the indoor space of the real estate in such a way that it can be used in spatial crowdsourcing environments. A website called SAMA was implemented to evaluate the proposed model in which the information is produced by non-professional contributors using online collaborative tools. Although the description of residential properties by the use of voluntary information might not have enough accuracy, quality, and security, it can offer helpful information to people within the shortest possible time and at the lowest possible cost. Two of the main challenges in crowdsourcing are quality and motivation. The solution proposed by this study to ensure quality is to involve the comments of visitors on each real estate. Also, a solution to motivate people to gather information in this environment is considered, with anybody who enters demographic data, physical condition, and purpose of use from SAMA's website, being able to find the real estate for free.

Finally, the topological relation criterion, color, directional relations, geographic situation, the height of the ceiling to the floor, and the space shape were selected. Despite presenting an almost perfect description of the real estate, these criteria have the lowest correlation among them. Finally, according to the survey, the proposed model was offered to two groups, with only one group having seen the real estate beforehand. The satisfaction of participants and the impact of the tools provided by the website were assessed. The results showed that the sketch plan is the most effective tool in visualizing and remembering the indoor space of the real estate in both groups. The effect of this tool was also higher in men than in women. The effectiveness of the provided tools showed that people who had never seen the property found the sketch, inflatable, photo and text the most effective in visualizing the interior, respectively. In the other group that had previously seen the property, the sketch, photo, text, and virtual tour had the most impact, respectively. The results also showed that $78.75 \%$ of SAMA users were satisfied.

Based on these promising results, the proposed model can be applied to visually describe the indoor space of real estate in crowd-sourcing environments. However, it should be noted that the following aspects of the proposed model should be investigated in future studies: First, the automatic drawing of the sketches by the system; second, evaluating the impact of gender on drawing the sketch plan; third, assessing the accuracy of drawing the sketch plan; fourth, investigating the strategies can be used to encourage greater participation of people in collecting information; finally, offering more services to the users in order to satisfy them. 


\section{References}

Allen, M. T., Cadena, A., Rutherford, J., \& Rutherford, R. C. (2015). Effects of Real Estate Brokers' Marketing Strategies: Public Open Houses, Broker Open Houses, MLS Virtual Tours, and MLS Photographs. Journal of Real Estate Research, 37(3), 343-369.

António, C. A. C., Monteiro, J. B., \& Afonso, C. F. (2014). Optimal topology of urban buildings for maximization of annual solar irradiation availability using a genetic algorithm. Applied Thermal Engineering, 73(1), 424-437.

Antoniou, V., \& Skopeliti, A. (2015). Measures and indicators of VGI quality: An overview. ISPRS annals of the photogrammetry, remote sensing and spatial information sciences, 2, 345.

Becker, T., Nagel, C., \& Kolbe, T. H. (2009). A multilayered space-event model for navigation in indoor spaces. In 3D geo-information sciences (pp. 61-77). Springer.

Boumová, I., \& Zdráhalová, J. (2016). The Apartment with the Best Floor Plan Layout: Architects versus Non-architects. Critical Housing Analysis, 3(1), 30-41.

Capineri, C., Haklay, M., Huang, H., Antoniou, V., Kettunen, J., Ostermann, F., \& Purves, R. (2016). European handbook of crowdsourced geographic information. Ubiquity Press.

Chen, G., Yu, L., Ng, W. S., Wu, H., \& Kunasegaran, U. N. (2017). STA: A Spatio-Temporal Thematic Analytics Framework for Urban Ground Sensing. International Conference on Advanced Data Mining and Applications.

Ching, Y. S. (2018). Virtual tour guide software UTAR].

Chow, T. E., Dede-Bamfo, N., \& Dahal, K. R. (2016). Geographic disparity of positional errors and matching rate of residential addresses among geocoding solutions. Annals of GIS, 22(1), 29-42.

Falomir, Z., Museros, L., Castelló, V., \& Gonzalez-Abril, L. (2013). Qualitative distances and qualitative image descriptions for representing indoor scenes in robotics. Pattern Recognition Letters, 34(7), 731-743.

Fasolo, P. J. (2016). Using crowd sourcing to change the real estate landscape.

Frontczak, M., \& Wargocki, P. (2011). Literature survey on how different factors influence human comfort in indoor environments. Building and Environment, 46(4), 922-937.

Ghuzlan, K. A., \& Al-Omari, B. H. (2016). Parking Demand for Residential Apartment Buildings in Jordan. Institute of Transportation Engineers. ITE Journal, 86(7), 32.

Gunnar, M., \& Mats, L. (2004). Annotating Mobile Multimedia Messages with Spatio-temporal Information. Geographic Information Sciences, 10(2), 139-148.

Gustafson, J., Bell, L., Beskow, J., Boye, J., Carlson, R., Edlund, J., Granström, B., House, D., \& Wirén, M. (2000). AdApt-a multimodal conversational dialogue system in an apartment domain. The Sixth International Conference on Spoken Language Processing (ICSLP), Beijing, China,

Ho, H.-P., Chang, C.-T., \& Ku, C.-Y. (2015). House selection via the internet by considering homebuyers' risk attitudes with S-shaped utility functions. European Journal of Operational Research, 241(1), 188-201.

Hosseinpour, M., Malek, M. R., \& Claramunt, C. (2019). Socio-spatial influence maximization in location-based social networks. Future Generation Computer Systems, 101, 304-314.

Jamali, A., Abdul Rahman, A., \& Boguslawski, P. (2016). 3D topologial indoor building modeling integrated with open street map.

Kaklauskas, A., Zavadskas, E. K., Banaitis, A., \& Šatkauskas, G. (2007). Defining the utility and market value of a real estate: a multiple criteria approach. International Journal of Strategic Property Management, 11(2), 107-120.

Kalantari, M., \& Nechifor, M. (2016). Accuracy and utility of the Structure Sensor for collecting 3D indoor information. Geo-spatial information science, 19(3), 202-209.

Kurraz, H. A., \& Ziara, M. M. (2015). Towards lowering the cost of houses in Palestine: New perspective. IUG Journal of Natural Studies, 15(2).

Le Yaouanc, J.-M., Saux, É., \& Claramunt, C. (2010). A semantic and language-based representation of an environmental scene. GeoInformatica, 14(3), 333-352.

Lee, S., \& Ha, M. (2013). Customer interactive building information modeling for apartment unit design. Automation in Construction, 35, 424-430.

Lin, Z., Anderson, G. D., \& Anderson, T. (2003). Enabling Real Estate Businesses on the Web: From EBusiness Model to The Application Services. 
Lu, D., Liu, X., \& Qian, X. (2016). Tag-based image search by social re-ranking. IEEE Transactions on Multimedia, 18(8), 1628-1639.

Medjdoub, B., \& Yannou, B. (2000). Separating topology and geometry in space planning. Computeraided design, 32(1), 39-61.

Meyers-Levy, J., \& Zhu, R. (2007). The influence of ceiling height: The effect of priming on the type of processing that people use. Journal of Consumer Research, 34(2), 174-186.

Mohammadi, N., \& Malek, M. (2015a). Artificial intelligence-based solution to estimate the spatial accuracy of volunteered geographic data. Journal of Spatial Science, 60(1), 119-135.

Mohammadi, N., \& Malek, M. (2015b). VGI and reference data correspondence based on locationorientation rotary descriptor and segment matching. Transactions in GIS, 19(4), 619-639.

Montoya, L. (2003). Geo-data acquisition through mobile GIS and digital video: an urban disaster management perspective. Environmental Modelling \& Software, 18(10), 869-876.

Muhanna, W., \& Wolf, J. (2002). The impact of e-commerce on the real estate industry: Baen and Guttery revisited. Journal of Real Estate Portfolio Management, 8(2), 141-152.

Oberfeld, D., Hecht, H., \& Gamer, M. (2010). Surface lightness influences perceived room height. The Quarterly Journal of Experimental Psychology, 63(10), 1999-2011.

Omidipoor, M., Jelokhani-Niaraki, M., \& Samany, N. N. (2019). A Web-based geo-marketing decision support system for land selection: a case study of Tehran, Iran. Annals of GIS, 25(2), 179-193.

Pekkonen, M., Du, L., Skön, J.-P., Raatikainen, M., \& Haverinen-Shaughnessy, U. (2015). The influence of tenure status on housing satisfaction and indoor environmental quality in Finnish apartment buildings. Building and Environment, 89, 134-140.

Poursaeed, O., Matera, T., \& Belongie, S. (2018). Vision-based real estate price estimation. Machine Vision and Applications, 29(4), 667-676.

Sahraoui, Y., Youssoufi, S., \& Foltête, J.-C. (2016). A comparison of in situ and GIS landscape metrics for residential satisfaction modeling. Applied Geography, 74, 199-210.

Salleh, S. A., Salleh, W. M. N. W., Nawawi, A. H., \& Sadek, E. S. S. M. (2008). The Integration of 3D GIS and Virtual Technology in the Design and Development of Residential Property Marketing Information System (GRPMIS). Computer and Information Science, 1(4), 37.

Seiler, M., Madhavan, P., \& Liechty, M. (2012). Toward an understanding of real estate homebuyer internet search behavior: an application of ocular tracking technology. Journal of Real Estate Research, 34(2), 211-241.

Singh, R., Woo, J., Khan, N., Kim, J., Lee, H. J., Rahman, H. A., Park, J., Suh, J., Eom, M., \& Gudigantala, N. (2019). Applications of Machine Learning Models on Yelp Data. Asia Pacific Journal of Information Systems, 29(1), 117-143.

Soleimani, S. (2015). Landscape Description in Volunteered Geographic Information (VGI) Using Spatial and Temporal Relationships. Unpublished M. Sc. Thesis, KNT University, Tehran, Iran (In Persian).

Sonawane, M. B., \& Mhaske, S. Y. (2016). Daylighting estimation and analysis in residential apartment building: GIS based approach. IOP Conference Series: Earth and Environmental Science,

Uttal, D. H., Fisher, J. A., \& Taylor, H. A. (2006). Words and maps: developmental changes in mental models of spatial information acquired from descriptions and depictions. Developmental Science, 9(2), 221-235.

Vartanian, O., Navarrete, G., Chatterjee, A., Fich, L. B., Gonzalez-Mora, J. L., Leder, H., Modroño, C., Nadal, M., Rostrup, N., \& Skov, M. (2015). Architectural design and the brain: effects of ceiling height and perceived enclosure on beauty judgments and approach-avoidance decisions. Journal of environmental psychology, 41, 10-18.

Veitch, J., Christoffersen, J., \& Galasiu, A. (2012). Daylight and View through Residential Windows: Effects on Well-being. LD+ A Magazine (October 1, 2012).

Zeinali, M. (2013). Faculty of Geoinformation and Real Estate Universiti Teknologi Malaysia.

Zhao, J., Zhu, Q., Du, Z., Feng, T., \& Zhang, Y. (2012). Mathematical morphology-based generalization of complex 3D building models incorporating semantic relationships. ISPRS Journal of Photogrammetry and Remote Sensing, 68, 95-111.

Zhao, S., Pan, G., Zhao, Y., Tao, J., Chen, J., Li, S., \& Wu, Z. (2016). Mining user attributes using largescale app lists of smartphones. IEEE Systems Journal, 11(1), 315-323. 